\title{
Adsorption of Phosphate from Aqueous Solution Using an Iron-Zirconium Binary Oxide Sorbent
}

\author{
Zongmin Ren • Lina Shao • Gaosheng Zhang
}

Received: 14 December 2011 / Accepted: 17 April 2012 /Published online: 5 May 2012

(C) Springer Science+Business Media B.V. 2012

\begin{abstract}
In this study, an iron-zirconium binary oxide with a molar ratio of $4: 1$ was synthesized by a simple coprecipitation process for removal of phosphate from water. The effects of contact time, initial concentration of phosphate solution, temperature, $\mathrm{pH}$ of solution, and ionic strength on the efficiency of phosphate removal were investigated. The adsorption data fitted well to the Langmuir model with the maximum $\mathrm{P}$ adsorption capacity estimated of $24.9 \mathrm{mg} \mathrm{P} / \mathrm{g}$ at $\mathrm{pH} 8.5$ and $33.4 \mathrm{mg} \mathrm{P} / \mathrm{g}$ at $\mathrm{pH}$ 5.5. The phosphate adsorption was $\mathrm{pH}$ dependent, decreasing with an increase in $\mathrm{pH}$ value. The presence of $\mathrm{Cl}^{-}, \mathrm{SO}_{4}{ }^{2-}$, and $\mathrm{CO}_{3}{ }^{2-}$ had little adverse effect on phosphate removal. A desorbability of approximately $53 \%$ was observed with $0.5 \mathrm{M} \mathrm{NaOH}$, indicating a relatively strong bonding between the adsorbed $\mathrm{PO}_{4}{ }^{3-}$ and the sorptive sites on the surface of the adsorbent. The phosphate uptake was mainly achieved through the replacement of surface hydroxyl groups by the phosphate species and formation of inner-
\end{abstract}

Z. Ren $\cdot$ L. Shao $\cdot$ G. Zhang $(\varangle)$

Key Laboratory of Coastal Zone Environmental Processes,

Yantai Institute of Coastal Zone Research(YIC),

Chinese Academy of Sciences(CAS),

Shandong Provincial Key Laboratory

of Coastal Zone Environmental Processes, YICCAS,

Yantai, Shandong 264003, People's Reupublic of China

e-mail: gszhang@yic.ac.cn

L. Shao

School of Environmental and Municipal Engineering,

Lanzhou Jiaotong University,

Lanzhou 730070, China sphere surface complexes at the water/oxide interface. Due to its relatively high adsorption capacity, high selectivity and low cost, this Fe-Zr binary oxide is a very promising candidate for the removal of phosphate ions from wastewater.

Keywords Fe-Zr binary oxide $\cdot$ Phosphate removal Adsorption $\cdot$ Mechanism

\section{Introduction}

The presence of trace amounts of phosphate (even less than $1 \mathrm{ppm}$ ) in treated wastewaters from municipalities and industries is often responsible for eutrophication, which leads to short- and long-term environmental and aesthetic problems in lakes, coastal areas, and other confined water bodies (Ouz et al. 2003). To protect aquatic quality, waste water containing phosphate must be treated to meet the discharge limit for phosphate (Puckett 1995; Zhao and Sengupta 1998; Ugurlu and Salman 1998). As this discharge limit is becoming more and more stringent, even further treatment of the effluent is required. For example, in China, the emission standard for the new-built urban sewage treatment plant will be upgraded to GB $1 \mathrm{~A}(\mathrm{TP}=0.5 \mathrm{mg} / \mathrm{L})$ from $\mathrm{GB} 1 \mathrm{~B}$ $(\mathrm{TP}=1.0 \mathrm{mg} / \mathrm{L})$, which puts forward a higher demand of phosphorus removal.

Conventional phosphorus removal methods from wastewater include chemical precipitation (Donnert and Salecker 1999), biological processes (De La Noue 
and de Pauw 1988; L. De-Bashan and Bashan 2004), reverse osmosis (Van Voorthuizen et al. 2005) and sorption processes (Morse et al. 1998; Kang et al. 2003). Among these techniques, adsorption is a promising method to treat waste water, especially at lower phosphate concentrations, which pose a challenge to the use of the traditional flocculation methods (Seida and Nakano 2002). In recent decades, booming studies have been focused on the selection of ideal P adsorption materials (Agyei et al. 2000; Arias et al. 2001; Khelifi et al. 2002; Tanada et al. 2003; Zeng et al. 2004). Among them, hydrous zirconium oxide has remarkable selectivity to phosphoric ion (Urnius et al. 2000), and also high resistance against attacks by acids, alkalis, oxidants, and reductants (Suzuki et al. 2000). Previous studies (Chitrakar et al. 2006; Liu et al. 2008; Biswas et al. 2008) have found that the zirconium oxide has a high $\mathrm{P}$ adsorption capacity and can be used for $\mathrm{P}$ removal from water. However, due to its relatively high cost, the application of pure zirconium oxide for $\mathrm{P}$ removal is not cost-effective. On the other hand, iron oxides-based materials (Zeng et al. 2004; Arias et al. 2006; Rentza et al. 2009) were also reported for phosphate removal with good performance. In addition, iron oxides have the favorable characteristics of environmental friendliness, chemical stability (low solubility), easy accessibility, and low cost.

Recently, synthesis of phosphate adsorbents using two (or more) different metal oxides has gained more attentions, since the synthesized composite can inherit the advantages of parent materials. Many of these adsorbents have shown much promise for the removal of phosphate from water. For example, Zhang et al. (2009) reported that a Fe-Mn binary oxide had a high $\mathrm{P}$ sorption capacity of $36 \mathrm{mg} \mathrm{g}$ at $\mathrm{pH}$ 5.6. Harver and Rhue (2008) reported that mixed Al-Fe hydr(oxides) were effective for P removal. Tian et al. (2009) showed that the mixed lanthanum/aluminum-pillared montmorillonite had a P sorption capacity of $13.0 \mathrm{mg} / \mathrm{g}$. Thus, it is expected that an iron-zirconium composite material originated from the combination of iron oxide and zirconium oxide may take full use of the advantages of both parent materials and have the potential for phosphate removal. In our previous studies (Ren et al. 2011), an iron-zirconium ( $\mathrm{Fe}-\mathrm{Zr}$ ) binary oxide was synthesized and was found to have high adsorption capacities towards both arsenate and arsenite. Furthermore, phosphate was found to be the most competitive anion for arsenic adsorption by the binary oxide.
However, little information is available for phosphate adsorption on this $\mathrm{Fe}-\mathrm{Zr}$ binary oxide.

In the present study, the kinetics and isotherm of phosphate adsorption by the $\mathrm{Fe}-\mathrm{Zr}$ binary oxide were studied. The influences of different experimental parameters such as solution $\mathrm{pH}$, ionic strength, competitive anions on phosphate removal as well as phosphate desorption were also investigated. Moreover, phosphate adsorption mechanism was elucidated in this paper.

\section{Materials and Methods}

\subsection{Materials}

All chemicals are analytical grade and used without further purification. Reaction vessels (glass) were cleaned with $1 \% \mathrm{HNO}_{3}$ and rinsed several times with deionized water before use. Phosphate stock solution was prepared by dissolving the anhydrous potassium dihydrogen orthophosphate $\left(\mathrm{KH}_{2} \mathrm{PO}_{4}\right)$ in deionized water. Phosphate working solutions were freshly prepared by diluting phosphate stock solution with appropriate amounts of deionized water.

\subsection{Preparation of $\mathrm{Fe}-\mathrm{Zr}$ Binary Oxide}

The Fe-Zr binary oxide was prepared according to the following procedure, which has been described in our previous publication (Ren et al. 2011): Ferric chloride hexahydrate $\left(\mathrm{FeCl}_{3} \cdot 6 \mathrm{H}_{2} \mathrm{O}, 0.05 \mathrm{~mol}\right)$ and zirconyl chloride octahydrate $\left(\mathrm{ZrOCl}_{2} \cdot 8 \mathrm{H}_{2} \mathrm{O}, 0.0125 \mathrm{~mol}\right)$ were dissolved in $400 \mathrm{ml}$ deionized water. Under vigorous magnetic-stirring, sodium hydroxide solution (2 M) was added dropwise to raise the solution $\mathrm{pH}$ to around 7.5. After addition, the formed suspension was continuously stirred for $1 \mathrm{~h}$, aged at room temperature for $4 \mathrm{~h}$ and then washed several times with deionized water. The suspension was filtrated and dried at $65^{\circ}$ $\mathrm{C}$ for $4 \mathrm{~h}$. The dry material was crushed and stored in a desiccator for use. The obtained material appeared in the form of fine powder.

\subsection{Batch Adsorption Tests}

\subsubsection{Adsorption Kinetics}

The kinetics experiments were carried out at room temperature $\left(25 \pm 1{ }^{\circ} \mathrm{C}\right)$. Defined amount of phosphate 
stock solution was added in a 1,000-ml glass vessel. Then, corresponding amount of deionized water was added to make $750 \mathrm{ml}$ of 5 or $10 \mathrm{mg} / \mathrm{L}$ phosphate solution. The ionic strength was maintained as $0.01 \mathrm{M}$ by adding $0.638 \mathrm{~g}$ sodium nitrate. After the solution $\mathrm{pH}$ was adjusted to $5.5 \pm 0.1$ by adding $0.1 \mathrm{M} \mathrm{HCl}$ and/or $\mathrm{NaOH}, 0.15 \mathrm{~g}$ of $\mathrm{Fe}-\mathrm{Zr}$ binary oxide was added to obtain a $0.2 \mathrm{~g} / \mathrm{L}$ suspension. The suspension was mixed with a magnetic stirrer at an agitation speed of $140 \mathrm{rpm}$, and the $\mathrm{pH}$ was maintained at $5.5 \pm 0.1$ throughout the experiment by addition of the dilute acid and/or base solutions. Approximately $5 \mathrm{ml}$ aliquots were taken from the vessel at predetermined times. The samples were immediately filtered through a $0.45-\mu \mathrm{m}$ membrane filter. The concentrations of phosphate in the filtered solutions were determined using an inductively coupled plasma atomic emission spectroscopy (ICP-AES, Optima 2100 DV, Perkin Elmer Co., USA) at RF power of 1,300 W and wavelength of $213.618 \mathrm{~nm}$. Finally, the exhausted sorbents were taken out for further desorption studies.

\subsubsection{Effect of $p H$ and Ionic Strength}

To investigate the influence of $\mathrm{pH}$ and ionic strength on the phosphate adsorption, experiments were carried out by adding $10 \mathrm{mg}$ of the adsorbent sample into $150-\mathrm{mL}$ glass vessel, containing $50 \mathrm{ml}$ of $5 \mathrm{mg} / \mathrm{L}$ phosphate solution. The ionic strength of the solutions varied from 0.001 to $0.1 \mathrm{M}$ by adding $\mathrm{NaNO}_{3}$. The $\mathrm{pH}$ of the solutions was adjusted every $4 \mathrm{~h}$ with dilute $\mathrm{HCl}$ or/and $\mathrm{NaOH}$ solution to designated values in the range of 3-11 during shaking process. The equilibrium $\mathrm{pH}$ was measured and the supernatant was filtered through a $0.45-\mu \mathrm{m}$ membrane after the solutions were mixed for $24 \mathrm{~h}$. Then, the residual phosphate concentration in the supernatant solutions was determined.

\subsubsection{Adsorption Isotherm}

Phosphate adsorption isotherm was determined using batch tests at the $\mathrm{pH}$ values of $5.5 \pm 0.1$ and $8.5 \pm 0.1$, respectively. Initial phosphate concentration was varied from 2 to $40 \mathrm{mg} / \mathrm{L}$. In each test, $10 \mathrm{mg}$ of the adsorbent sample was loaded in the $150-\mathrm{mL}$ glass vessel and $50 \mathrm{ml}$ of solution containing different amount of phosphate was then added to the vessel. Ionic strength of the solution was adjusted to $0.01 \mathrm{M}$ with $\mathrm{NaNO}_{3}$. The vessels were shaken on an orbit shaker at $140 \mathrm{rpm}$ for $24 \mathrm{~h}$ at $25 \pm 1{ }^{\circ} \mathrm{C}$. After the reaction period, all samples were filtered by a $0.45-\mu \mathrm{m}$ membrane filter and analyzed for phosphate. The quantity of adsorbed phosphate was calculated by the difference of the initial and residual amounts of phosphate in solution divided by the weight of the adsorbent.

Both Freundlich and Langmuir models (Freundlich 1906; Langmuir 1916) were employed to describe the experimental results of phosphate adsorption. The Freundlich equation is represented as follows:

$q_{e}=K_{F} C_{e}^{1 / n}$

where $q_{\mathrm{e}}$ is the amount of phosphate adsorbed on the solid phase (milligrams per gram), $C_{\mathrm{e}}$ is the equilibrium phosphate concentration in solution phase (milligrams per liter), $K_{\mathrm{F}}$ is roughly an indicator of the adsorption capacity, and $n$ is the heterogeneity factor which has a lower value for more heterogeneous surfaces.

The Langmuir equation can be written in the following form:

$q_{e}=q_{m} \frac{K_{L} C_{e}}{1+K_{L} C_{e}}$

where $q_{\mathrm{e}}$ and $C_{\mathrm{e}}$ are previously denoted, $K_{L}$ is the equilibrium adsorption constant related to the affinity of binding sites (liters per milligram); and $q_{\mathrm{m}}$ is the maximum amount of the phosphate per unit weight of adsorbent for complete monolayer coverage.

\subsubsection{Effect of Coexisting Anions}

The effect of common coexisting ions in wastewater such chloride, sulphate, and carbonate on the adsorption of phosphate was investigated by adding 1.0 or $10 \mathrm{mM}$ of sodium chloride, sodium sulphate, and sodium carbonate to $5 \mathrm{mg} / \mathrm{L}$ of phosphate solution. The solution $\mathrm{pH}$ was adjusted to 7.0. A defined amount $(10 \mathrm{mg})$ of $\mathrm{Fe}-\mathrm{Zr}$ binary oxide was added and the solutions were agitated at $140 \mathrm{rpm}$ for $24 \mathrm{~h}$ at $25 \pm 1{ }^{\circ} \mathrm{C}$. After filtration by a $0.45-\mu \mathrm{m}$ membrane filter, the residual concentration of phosphate was analyzed using ICP-AES.

\subsubsection{Desorption of Phosphate}

For the study of desorption, the exhausted adsorbent powders were collected after filtration of the suspension from the above tests. Fifty milligrams of exhausted $\mathrm{Fe}-\mathrm{Zr}$ binary oxide was added into each $150-\mathrm{mL}$ vessel 
containing $50 \mathrm{~mL}$ solution with different concentrations of $\mathrm{NaOH}(0,0.001,0.01,0.1$, and $0.5 \mathrm{M})$. Appropriate $\mathrm{NaNO}_{3}$ was then added to adjust the ionic strength of the solution to $0.01 \mathrm{M}$. The solutions were agitated at $140 \mathrm{rpm}$ for $4 \mathrm{~h}$ at $25 \pm 1{ }^{\circ} \mathrm{C}$. The suspension solutions were then filtered and analyzed for phosphate according to the method described previously. The quantity of desorbed phosphate was determined by the amount of phosphate in the solution after the desorption experiment. The P desorbability was defined as the ratio of the desorbed $\mathrm{P}$ over the total $\mathrm{P}$ adsorbed by the adsorbent.

\subsubsection{Characterization of Adsorbent Before and After Phosphate Adsorption}

A Zeta potential analyzer (Zetasizer 2000, Malvern Co., UK) was used to analyze the Zeta potentials of $\mathrm{Fe}-\mathrm{Zr}$ binary oxide particles before and after phosphate adsorption. The content of the $\mathrm{Fe}-\mathrm{Zr}$ binary oxide in the solution was about $200 \mathrm{mg} / \mathrm{L}$ and initial phosphate concentration was $5 \mathrm{mg} / \mathrm{L}$. $\mathrm{NaNO}_{3}$ was used as background electrolyte to maintain an approximately constant ionic strength of $0.01 \mathrm{M}$. After mixing for $72 \mathrm{~h}$ to ensure the achievement of adsorption equilibrium, $20 \mathrm{ml}$ of oxide suspension was transferred to a sample tube. Zeta potential of the suspension was then measured by electrokinetic analysis.

FTIR spectra were collected on a Nicolet 5700 FTIR spectrophotometer (Nicolet Co., USA) using transmission model. Samples for FTIR determination were ground with spectral grade $\mathrm{KBr}$ in an agate mortar. IR spectra of phosphate adsorbed on the binary oxide were obtained as dry samples in $\mathrm{KBr}$ pellets corresponding to $5 \mathrm{mg}$ of sample in approximately $200 \mathrm{mg}$ of spectral grade KBr. All IR measurements were carried out at room temperature.

\section{Results and Discussion}

\subsection{Adsorbent Properties}

The prepared $\mathrm{Fe}-\mathrm{Zr}$ binary oxide is amorphous and poorly crystalline, and its main particle size is in the range of 2-30 $\mu \mathrm{m}$. It has a high BET surface area of $339 \mathrm{~m}^{2} / \mathrm{g}$ and the micropore and mesopore volumes are 0.026 and $0.281 \mathrm{~cm}^{3} \mathrm{~g}^{-1}$, respectively.

\subsection{Adsorption Kinetics}

Kinetic experiments were carried out to determine the rate of phosphate sorption from the water by the $\mathrm{Fe}-\mathrm{Zr}$ binary oxide. The initial phosphate concentrations were 5 and $10 \mathrm{mg} / \mathrm{L}$, respectively, and the $\mathrm{pH}$ value of solution was maintained at $5.5 \pm 0.1$. Figure 1 shows the change of adsorbed phosphate as a function of contact time. Obviously, the sorption process could be divided into two steps, a quick step and a slow one. For the system with initial phosphate concentration of $5 \mathrm{mg} / \mathrm{L}$, the adsorption rate was fast in the first step, and over $93 \%$ of the equilibrium adsorption capacity was achieved within the beginning $1.5 \mathrm{~h}$. This may be contributed to the smaller particle size
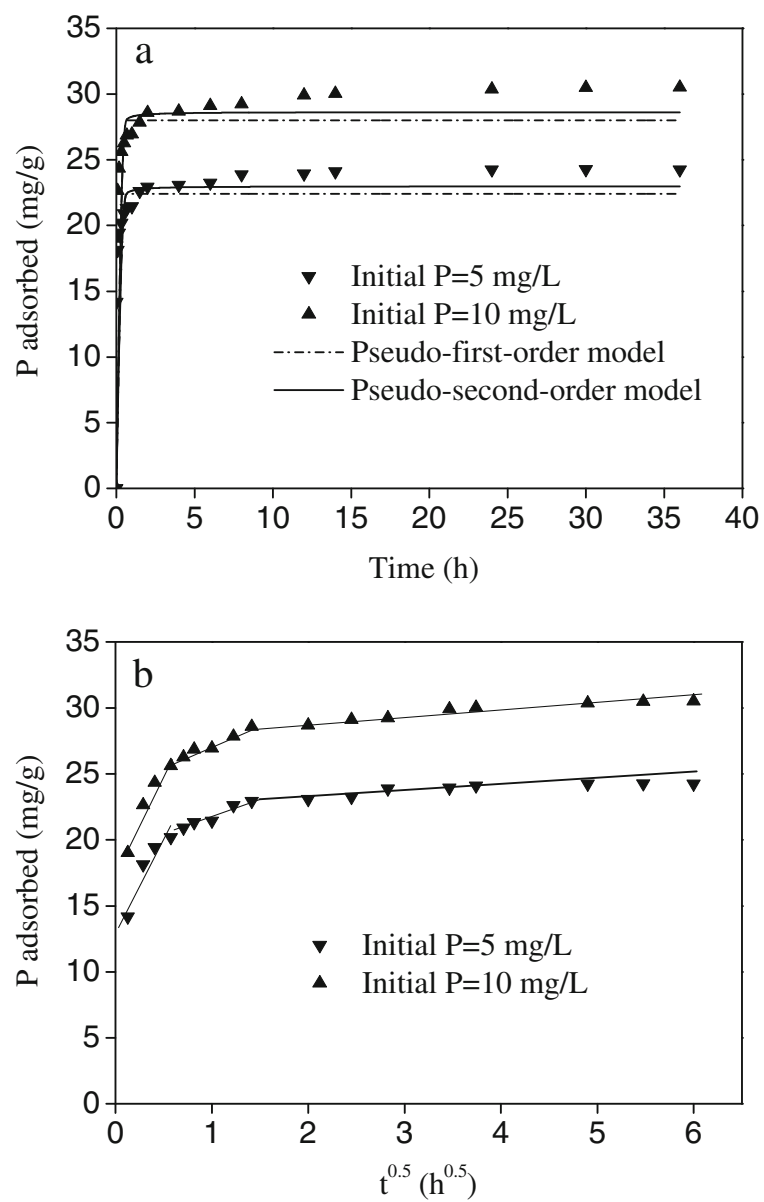

Fig. 1 Adsorption kinetics of phosphate on $\mathrm{Fe}-\mathrm{Zr}$ binary oxide adsorbent in a $200 \mathrm{mg} \mathrm{L}^{-1}$ suspension at $\mathrm{pH} 5.5 \pm 0.1$ and two initial phosphate concentrations $\left(5 \mathrm{mg} \mathrm{L}^{-1}\right.$ and $\left.10 \mathrm{mg} \mathrm{L}^{-1}\right)$. a fitting with pseudo-first-order and the pseudo-second-order models and $\mathbf{b}$ fitting with intraparticle diffusion model 
of $\mathrm{Fe}-\mathrm{Zr}$ binary oxide powders, which was favorable for the diffusion of phosphate molecules from bulk solution onto the active sites of the solid surface. In the following step, intraparticle diffusion might dominate and the adsorption slowed down. Another appropriate $5 \%$ removal percentage was observed with $8 \mathrm{~h}$. After $12 \mathrm{~h}$, about $99 \%$ of the maximum adsorption had taken place. The adsorption process of phosphate with an initial concentration of $10 \mathrm{mg} / \mathrm{L}$ is similar to that of $5 \mathrm{mg} / \mathrm{L}$, except for higher adsorption amounts. It could be concluded that $24 \mathrm{~h}$ was an adequate time for equilibrium to occur.

In order to evaluate the mechanism of adsorption and potential rate controlling steps such as mass transport and diffusion control processes, the experimental data (Fig. 1) were analyzed using different models. Initially, the pseudo-first-order and the pseudosecond-order models were tested to describe the sorption process (Fig. 1a). The mathematical representations of these models are given in Eqs. (3) and (4), respectively.

$\ln \left(q_{e}-q_{t}\right)=\ln q_{e}-k_{1} t$

$\frac{t}{q_{t}}=\frac{1}{k_{2} q_{e}^{2}}+\frac{t}{q_{e}}$

Table 1 presents the values of constants of the pseudo-first-order and pseudo-second-order kinetic models for adsorption of phosphate onto $\mathrm{Fe}-\mathrm{Zr}$ binary oxide. It is found that the kinetic data fitted better with pseudo-second-order model than pseudo-first-order model, which is evident from the higher determination coefficient values. This study showed that the pseudosecond-order model better represented the phosphate adsorption kinetics, suggesting that the adsorption process might be chemisorption.

The pseudo-second-order model is well describing the reaction kinetics, but it is limited in accuracy by considering adsorption as a single, one-step binding process. However, the intraparticle diffusion model may provide a more comprehensive view of adsorption as a series of distinct steps (D'Arcy et al. 2011). Therefore, it was also applied to describe the sorption process (Fig. 1b). The mathematical representation of this model is usually given in Eq. (5).

$q_{t}=k_{p} t^{0.5}+C$

where $q_{e}$ and $q_{t}$ are the adsorption capacities (milligrams of $\mathrm{P}$ per gram) of the adsorbent at equilibrium and at any time, $t$ (hour), respectively; $k_{1}$ (per hour) and $k_{2}$ (grams per milligram per hour) are the pseudofirst-order and pseudo-second-order rate constants for adsorption process, respectively. $k_{\mathrm{p}}$ is the intraparticle diffusion rate constant and $C$ is a constant gained from the intercept of plot of $q_{t}$ against $t^{0.5}$

Figure $1 \mathrm{~b}$ exhibits the results of experimental data fitted with intraparticle diffusion model. It clearly shows three linear sections and this multi-linearity indicates further the complexity of the adsorption process. The first linear step was a fast stage. This could be due to the quick transfer of phosphate anions from bulk phase to particle surface, since the adsorption was conducted in a well-agitated tank. For well-agitated system, film diffusion resistance will be quite small and pore diffusion will be rate controlling. The second linear portion was a moderate adsorption process, where the rate of adsorption was governed by the intraparticle diffusion in the pore structure. The third linear section was a very slow adsorption stage, relating to the steric hindrance from the adsorbed molecules.

\subsection{Adsorption Isotherm}

The equilibrium adsorption isotherm is fundamental in describing the interactive behavior between solutes and adsorbent, and is important for the design of adsorption system. Isotherm studies were conducted at two $\mathrm{pH}$ levels (5.5 and 8.5). Figure 2a shows a plot
Table 1 Adsorption rate constant obtained from pseudofirst-order model and pseudosecond-order model for various initial concentrations of phosphate

\begin{tabular}{llllllll}
\hline $\begin{array}{l}\text { Initial concentration } \\
(\mathrm{mg} / \mathrm{L})\end{array}$ & \multicolumn{2}{l}{ Pseudo-first-order model } & & \multicolumn{3}{l}{ Pseudo-second-order model } \\
\cline { 2 - 3 } & $q_{\mathrm{e}}(\mathrm{mg} / \mathrm{g})$ & $k_{1}\left(\mathrm{~h}^{-1}\right)$ & $R^{2}$ & & $q_{\mathrm{e}}(\mathrm{mg} / \mathrm{g})$ & $k_{2}(\mathrm{~g} / \mathrm{mg} \mathrm{h})$ & $R^{2}$ \\
\hline 5 & 22.4 & 56.7 & 0.899 & 23.0 & 3.02 & 0.953 \\
10 & 28.0 & 66.2 & 0.900 & 28.6 & 2.96 & 0.950 \\
\hline
\end{tabular}



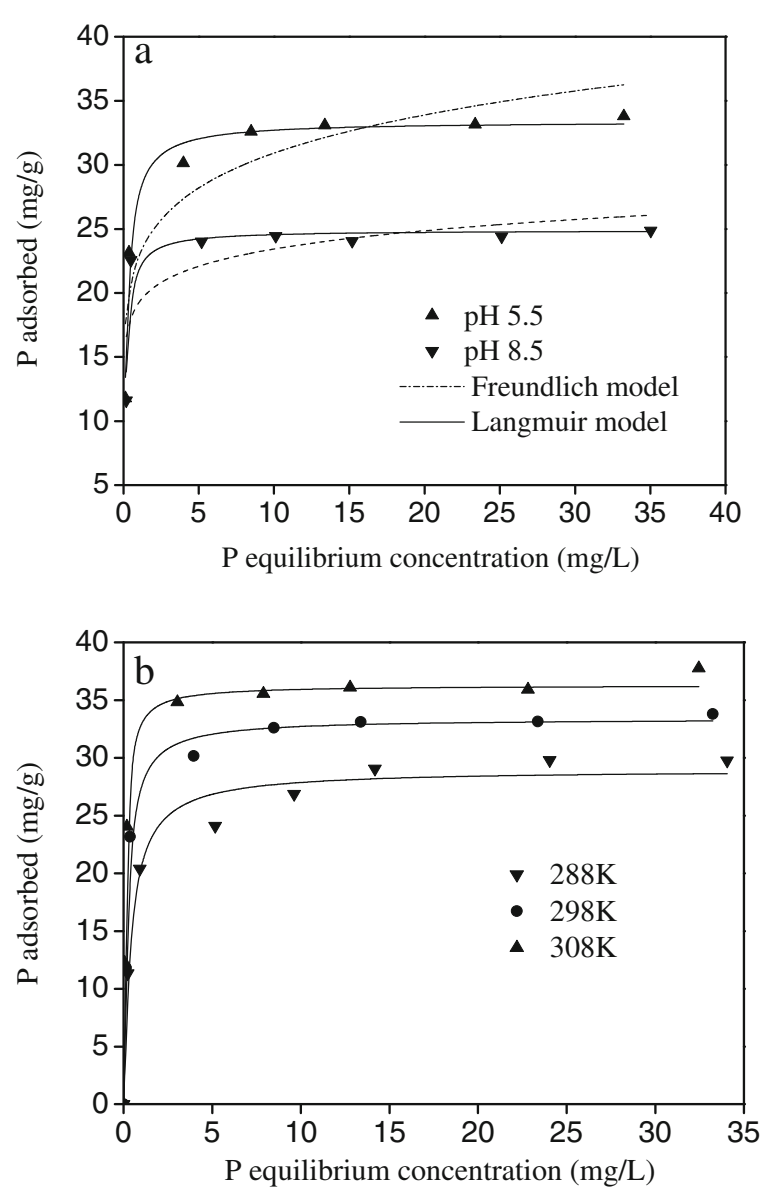

Fig. 2 Adsorption isotherms of phosphate on $\mathrm{Fe}-\mathrm{Zr}$ binary oxide a at two pHs in a $200 \mathrm{mg} \mathrm{L}^{-1}$ suspension and $298 \mathrm{~K}$ and $\mathbf{b}$ at different temperatures in a $200 \mathrm{mg} \mathrm{L}^{-1}$ suspension at $\mathrm{pH} 5.5 \pm 0.1$

of the uptake of phosphate by the adsorbent against the phosphate equilibrium concentration in the solution. Both Langmuir and Freundlich models were employed to describe the experimental data. The adsorption constants obtained from the isotherm are listed in Table 2.

Based on the correlation coefficient $\left(R^{2}\right)$ values, it is found that the Langmuir model is more suitable for describing the experimental data than Freundlich model at two $\mathrm{pH}$ levels. Although the Langmuir $q_{\max }$ value might not provide an accurate estimation of the longterm sorption capacity, it could still be useful in comparing alternative materials for wastewater treatment (Cheung and Venkitachalam 2000). The maximum $\mathrm{P}$ adsorption capacity of $\mathrm{Fe}-\mathrm{Zr}$ binary oxide is $33.4 \mathrm{mg} \mathrm{P} / \mathrm{g}$ at $\mathrm{pH} 5.5 \pm 0.1$, while $24.9 \mathrm{mg} \mathrm{P} / \mathrm{g}$ at $\mathrm{pH} 8.5 \pm 0.1$. This value is high as compared to the reported data in the literature (see in Table 3). Moreover, it could be found that this adsorbent had a high adsorption capacity towards phosphate under relatively lower equilibrium concentration (below $0.5 \mathrm{mg} / \mathrm{L}$ ). This indicates that it is much more suitable for treatment of the wastewater containing low level of phosphate.

Additionally, the effect of three different temperatures $(288,298$, and $308 \mathrm{~K})$ on phosphate adsorption was examined at $\mathrm{pH} 5.5 \pm 0.1$ and the results were presented in Fig. 2b. The adsorption isotherms were fitted by Langmuir model. The values of $K_{L}$ and $R^{2}$ at different temperature are listed in Table 4. Clearly, the adsorption capacity increased with increasing temperature which indicates that the adsorption process is endothermic in nature. Therefore, the increase of temperature is favoring the phosphate uptake by this binary oxide.

\subsection{Effect of $\mathrm{pH}$ and Ionic Strength on Phosphate Uptake}

As demonstrated in Fig. 3, the phosphate uptake was evidently dependent on $\mathrm{pH}$ with the greatest adsorption occurring under acidic conditions and decreased with increase in solution $\mathrm{pH}$. For example, the $\mathrm{PO}_{4}{ }^{3-}$ removal rate decreased from $100 \%$ at around $\mathrm{pH} 3.1$ to about $32 \%$ at $\mathrm{pH} 10.9$. Similar $\mathrm{pH}$ effect on phosphate ions sorption by iron or iron-based oxides has been reported by a number of authors (Ryden and McLaughlin 1977; Zhang et al. 2009). Such

Table 2 Langmuir and Freundlich isotherm constants for phosphate adsorption by Fe-Zr binary oxide at $25 \pm 1{ }^{\circ} \mathrm{C}$

\begin{tabular}{|c|c|c|c|c|c|c|}
\hline \multirow[t]{2}{*}{$\mathrm{pH}$} & \multicolumn{3}{|c|}{ Langmuir model } & \multicolumn{3}{|c|}{ Freundlich model } \\
\hline & $q_{m}\left(\mathrm{mg} \mathrm{g}^{-1}\right)$ & $K_{L}\left(\mathrm{~L} \mathrm{mg}^{-1}\right)$ & $R^{2}$ & $K_{\mathrm{F}}$ & $n$ & $R^{2}$ \\
\hline 5.5 & 33.40 & 4.73 & 0.990 & 22.79 & 7.55 & 0.800 \\
\hline 8.5 & 24.91 & 7.07 & 0.857 & 19.26 & 11.72 & 0.544 \\
\hline
\end{tabular}


Table 3 Comparison of maximum phosphate adsorption capacities for different adsorbents

\begin{tabular}{lllll}
\hline Adsorbent & $\begin{array}{l}\text { Equilibrium P concentration } \\
\text { range }(\mathrm{mg} / \mathrm{L})\end{array}$ & $\mathrm{pH}$ & $\begin{array}{l}\text { Maximum capacity } \\
(\mathrm{mg} \mathrm{P} / \mathrm{g})\end{array}$ & Reference \\
\hline Fe-Zr binary oxide & $0-35$ & 5.5 & 33.4 & Present study \\
Mesoporous $\mathrm{ZrO}_{2}$ & $0-280$ & $6.7-6.9$ & 29.7 & Liu et al. 2008 \\
Akaganéite & $0-280$ & 7.0 & 49 & Deliyanni et al. 2007 \\
Iron oxide tailings & $0-140$ & $6.6-6.8$ & 8 & Zeng et al. 2004 \\
Magnetic Fe-Zr binary oxide & $0-100$ & 4 & 13.6 & Long et al. 2011 \\
Red mud & $0-1$ & 5.5 & 0.23 & Huang et al. 2008 \\
Palygorskites & $0-150$ & $7.0-7.2$ & 4 & Ye et al. 2006 \\
Hydrous niobium oxide & $0-25$ & 2 & 13 & Rodrigues and Silva 2009 \\
La-doped vesuvianite & $0-4.0$ & 7.1 & 6.7 & Li et al. 2009 \\
\hline
\end{tabular}

phenomenon could be explained as follows: negativecharged $\mathrm{H}_{2} \mathrm{PO}_{4}{ }^{-}$and $\mathrm{HPO}_{4}{ }^{2-}$ are dominant phosphate species in the solution under the tested $\mathrm{pH}$ range (3-11). Lower $\mathrm{pH}$ is favoring the protonation of $\mathrm{Fe}-\mathrm{Zr}$ binary oxide surface and increased protonation is thought to increase the positively charged sites, enlarge the attraction force existing between the oxide surface and phosphate ions and therefore increase the amount of adsorption in the lower $\mathrm{pH}$ region. As solution $\mathrm{pH}$ increase, the negatively charged sorptive sites dominate gradually and more negatively charged phosphate species are also becoming dominant, which enhances the repulsion effect between the $\mathrm{Fe}-\mathrm{Zr}$ binary oxide and the phosphate ions. Therefore, the amount of phosphate uptake is consequently dropped. Fortunately, over $60 \%$ removal rate could be obtained even at $\mathrm{pH} 9.0$.

Clearly, the increase in ionic strength from 0.001 to $0.1 \mathrm{M}$ lead to a shift in the position of the $\mathrm{pH}$ edge towards the alkaline region, and also slightly enhanced the adsorption of phosphate in this range (6-11). The similar phenomenon was also observed by other researchers using iron-based metal oxides (Zhang et al. 2009; Giesler et al. 2005). Anions adsorbed through outer-sphere association are strongly sensitive

Table 4 Langmuir isotherm calculations at different temperatures

\begin{tabular}{llll}
\hline & \multicolumn{3}{l}{ Fe-Zr binary oxide $+\mathrm{P}$} \\
\cline { 2 - 4 } Temperature & $\begin{array}{l}q_{\max } \\
(\mathrm{mg} / \mathrm{g})\end{array}$ & $\begin{array}{l}K_{L} \\
\left(\mathrm{~L} \mathrm{mg} \mathrm{mg}^{-1}\right)\end{array}$ & $R^{2}$ \\
\hline $288 \mathrm{~K}$ & 28.97 & 2.51 & 0.981 \\
$298 \mathrm{~K}$ & 33.40 & 4.73 & 0.990 \\
$308 \mathrm{~K}$ & 36.28 & 9.98 & 0.996 \\
\hline
\end{tabular}

to ionic strength and the adsorption of these anions is suppressed by competition with weakly adsorbing anions such as $\mathrm{NO}_{3}{ }^{-}$since electrolytes also form outer-sphere complexes through electrostatic forces. On the contrary, anions adsorbed through innersphere association either show little sensitivity to ionic strength or respond to higher ionic strength with greater adsorption (McBride 1997). Thus, it indicates that the uptake of phosphate ions may probably take place through the formation of inner-sphere surface complexes at the water/oxide surface.

\subsection{Effect of Coexisting Anions}

Anions such as chloride, sulphate, and carbonate are commonly present in the wastewater, and could interfere in the uptake of phosphate by adsorbent through

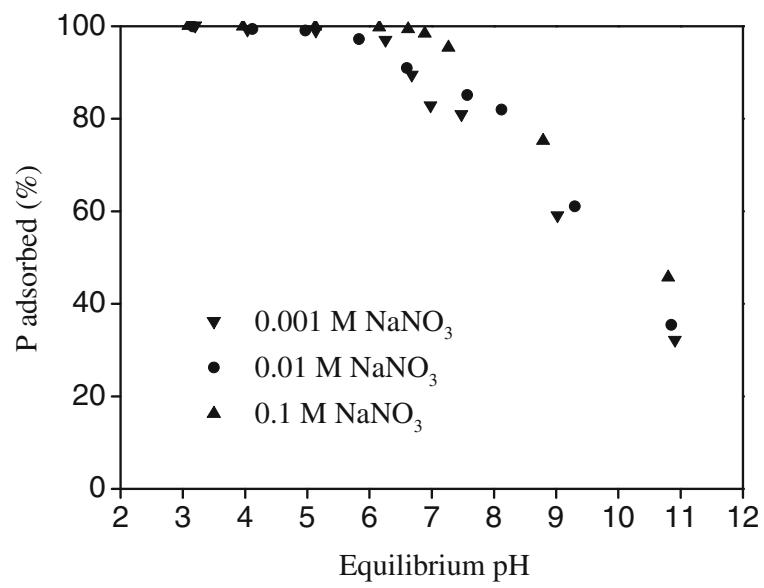

Fig. 3 Effect of pH on phosphate adsorption on $\mathrm{Fe}-\mathrm{Zr}$ binary oxide for different ionic strengths. Initial $\mathrm{P}$ concentration was $5 \mathrm{mg} / \mathrm{L}$ and adsorbent content was $200 \mathrm{mg} / \mathrm{L}$ 




Fig. 4 Influences of co-existing anions on phosphate uptake at $\mathrm{pH} 7.0 \pm 0.1$. Initial $\mathrm{P}$ concentration was $5 \mathrm{mg} / \mathrm{L}$ and adsorbent content was $200 \mathrm{mg} / \mathrm{L}$

competitive adsorption. Thus, the influences of these coexisting anions at three concentration levels (1.0, 10 , and $100 \mathrm{mM}$ ) on the phosphate adsorption were assessed at initial $\mathrm{pH}$ of 5.6 and the results were shown in Fig. 4. Only a slight decrease in phosphate removal was observed when the concentration of coexisting ions was increased from 1.0 to $10 \mathrm{mM}$. Obviously, the presence of these kinds of ions has no significant influence on the phosphate adsorption. This suggests that this binary oxide has high adsorption selectivity towards phosphate anions and has high potential to be used in real wastewater.

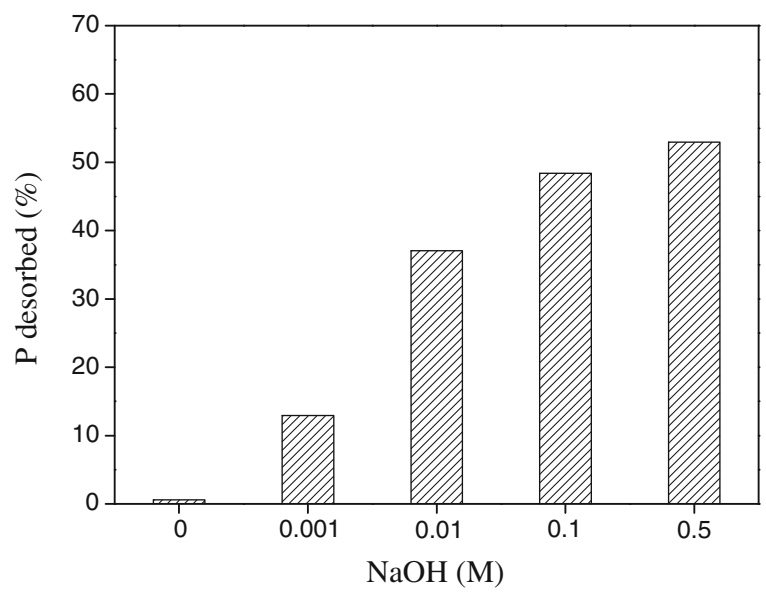

Fig. 5 Desorption of phosphate from P-loaded Fe-Zr binary oxide using different concentrations of $\mathrm{NaOH}$ solution at adsorbent dose $=1 \mathrm{~g} / \mathrm{L}$, agitation speed $=140 \mathrm{rpm}, T=25 \pm 1{ }^{\circ} \mathrm{C}$, equilibrium time $=6 \mathrm{~h}$

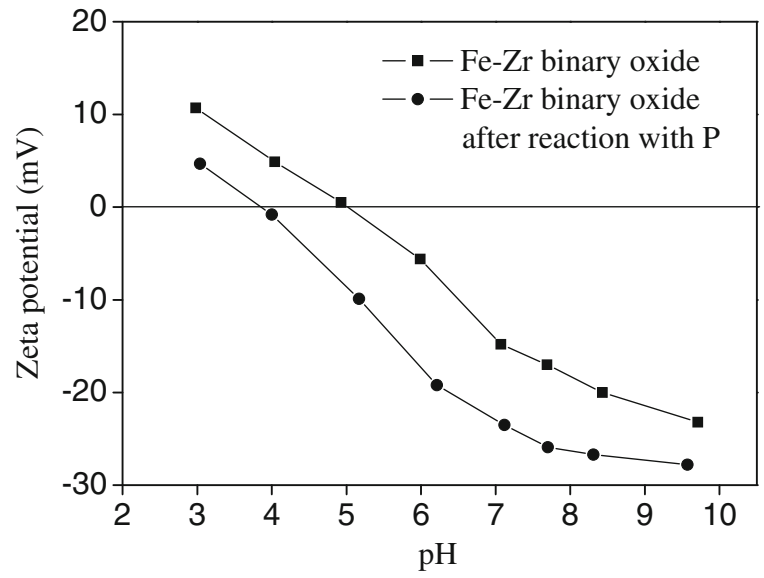

Fig. 6 Zeta potential of $\mathrm{Fe}-\mathrm{Zr}$ binary oxide before and after reaction with phosphate solution. $\mathrm{P}$ initial concentration was $5 \mathrm{mg} / \mathrm{L}$ and adsorbent content was $200 \mathrm{mg} / \mathrm{L}$

\subsection{Desorption of Phosphate}

The desorption of phosphate from the phosphateloaded $\mathrm{Fe}-\mathrm{Zr}$ binary oxide was evaluated using $\mathrm{NaOH}$ solutions with different concentrations. Figure 5 shows the results. It was found that the amount of phosphate desorption increased with the increase of alkalinity. A desorption of only $0.6 \%$ was obtained when the extracting solution was only $0.01 \mathrm{M} \mathrm{NaNO}_{3}$ solution without added $\mathrm{NaOH}$. About $48 \%$ of adsorbed phosphate was desorbed into the solution when the concentration of $\mathrm{NaOH}$ increased to $0.1 \mathrm{M}$. However, the further increase in $\mathrm{NaOH}$ concentration (up to $0.5 \mathrm{M}$ ) did not significantly enhanced the

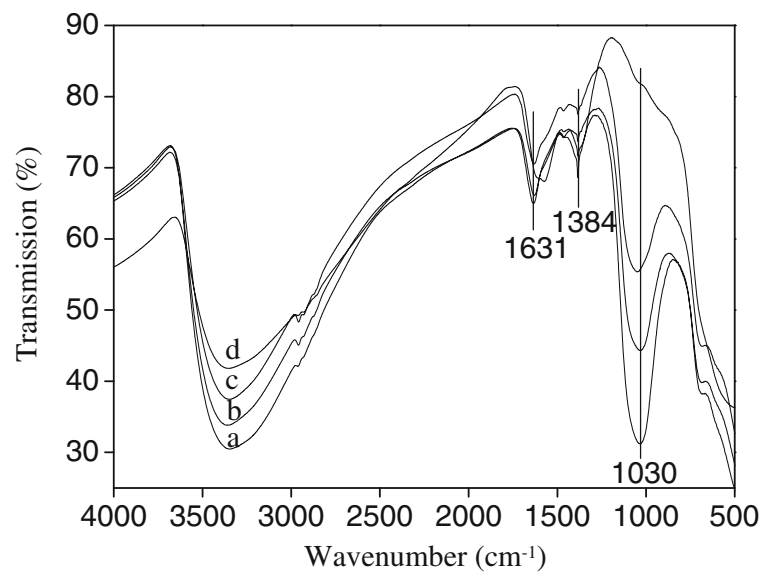

Fig. 7 FTIR spectra of Fe-Zr binary oxide (a) and after treatment in aqueous solutions of three different phosphate concentrations at $\mathrm{pH} 7.0, \mathbf{b} 5 \mathrm{mg} / \mathrm{L}, \mathbf{c} 10 \mathrm{mg} / \mathrm{L}$, and d $40 \mathrm{mg} / \mathrm{L}$ 
desorption of phosphate. These results indicate that the phosphate adsorption on the $\mathrm{Fe}-\mathrm{Zr}$ binary oxide is not completely reversible. This may be probably due to the relatively strong bonding between the active sites and the adsorbed phosphate, indicating that the phosphate was chemically adsorbed by the Fe- $\mathrm{Zr}$ binary oxide.

\subsection{Zeta Potential Measurement and FTIR Analysis}

The zeta potentials of the $\mathrm{Fe}-\mathrm{Zr}$ binary oxide suspensions before and after phosphate adsorption were measured. As shown in Fig. 6, the Fe-Zr binary oxide has an isoelectric point of about 5.1, which was decreased to about 3.9 after the phosphate adsorption. The specific adsorption of anions makes the surface of oxides more negatively charged, which results in a shift of the isoelectric point of adsorbent to a lower $\mathrm{pH}$ value (Hsia et al. 1994). Therefore, specific adsorption rather than a purely electrostastic interaction is further confirmed from the drop of isoelectric point at the aqueous phosphate/Fe- $\mathrm{Zr}$ binary oxide interface.

The FTIR spectra of Fe-Zr binary oxide before and after phosphate adsorption were obtained with the KBr-pressed disk technique and are shown in Fig. 7. For the original $\mathrm{Fe}-\mathrm{Zr}$ binary oxide, the strong and broad bands in the $3,500-3,300 \mathrm{~cm}^{-1}$ region may be assigned to the vibration of $\mathrm{O}-\mathrm{H}$ stretching and $1,631 \mathrm{~cm}^{-1}$ may be assigned to the deformation vibration of water molecules, indicating the presence of physisorbed water molecules on the oxide. Compared with spectrum of original $\mathrm{Fe}-\mathrm{Zr}$ binary oxide, two new peaks appeared at 1,384 and $1,030 \mathrm{~cm}^{-1}$, respectively, after phosphate adsorption. The peak at $1,384 \mathrm{~cm}^{-1}$ may be ascribed to the vibration of $\mathrm{NO}_{3}{ }^{-}$ because $\mathrm{NaNO}_{3}$ was used as background electrolyte. The bind at $1,030 \mathrm{~cm}^{-1}$ which is broad and intensive could be assigned to the asymmetry vibration of $\mathrm{P}-\mathrm{O}$ (Persson et al. 1996) and the intensity of this band increased obviously with the increase of phosphate concentration. This indicates that phosphate is mainly bound as a surface complex.

From the results of ionic strength influence experiment, analyses of zeta potential and FTIR spectra, a reasonable mechanism for phosphate adsorption on the $\mathrm{Fe}-\mathrm{Zr}$ binary oxide could be provided. Phosphate is adsorbed through the replacement of surface hydroxyl groups on the solid surface and formation of inner-sphere surface complexes. The possible reactions between phosphate and the surface of $\mathrm{Fe}-\mathrm{Zr}$ binary oxide $(\equiv \mathrm{M}-\mathrm{OH})$ could be presented as follows:

$$
\equiv \mathrm{M}-\mathrm{OH}+\mathrm{PO}_{4}^{3-}+\mathrm{H}^{+} \leftrightarrow \equiv \mathrm{M}-\mathrm{PO}_{4}^{2-}+\mathrm{H}_{2} \mathrm{O}
$$

$$
\equiv \mathrm{M}-\mathrm{OH}+\mathrm{PO}_{4}^{3-}+2 \mathrm{H}^{+} \leftrightarrow \equiv \mathrm{M}-\mathrm{HPO}_{4}^{-}+\mathrm{H}_{2} \mathrm{O}
$$

$$
\equiv \mathrm{M}-\mathrm{OH}+\mathrm{PO}_{4}^{3-}+3 \mathrm{H}^{+} \leftrightarrow \equiv \mathrm{M}-\mathrm{H}_{2} \mathrm{PO}_{4}+\mathrm{H}_{2} \mathrm{O}
$$

$2 \equiv \mathrm{M}-\mathrm{OH}+\mathrm{PO}_{4}^{3-}+2 \mathrm{H}^{+} \leftrightarrow \equiv \mathrm{M}_{2}-\mathrm{PO}_{4}^{-}+2 \mathrm{H}_{2} \mathrm{O}$

Where $-\mathrm{OH}$ is a hydroxyl group.

\section{Conclusions}

The Fe-Zr binary oxide with a molar ratio of 4:1 was prepared by a one-step coprecipitation method. The phosphate removal by this oxide was rather rapid and over $93 \%$ of the equilibrium adsorption capacity was achieved within the beginning $1.5 \mathrm{~h}$ under tested conditions. It was very effective for phosphate removal and the maximum $\mathrm{P}$ adsorption capacity estimated of $24.9 \mathrm{mg} \mathrm{P} / \mathrm{g}$ at $\mathrm{pH} 8.5$, and $33.4 \mathrm{mg} \mathrm{P} / \mathrm{g}$ at $\mathrm{pH}$ 5.5. The phosphate adsorption was $\mathrm{pH}$ dependent, decreasing with an increase in $\mathrm{pH}$ value. It has high selectivity towards phosphate ions and coexisting anions such as chloride, sulphate, and carbonate had little adverse effect on the uptake of phosphate. The phosphate anions may form inner-sphere surface complexes at the water/oxide interface, which is the main phosphate removal mechanism. Due to its relatively high adsorption capacity, high selectivity, and low cost, this $\mathrm{Fe}-\mathrm{Zr}$ binary oxide is a very promising candidate for the removal of phosphate ions from wastewater.

Acknowledgment This research was financially supported by the National Natural Science Foundation of China (grant no. 51178453). 


\section{References}

Agyei, N., Strydom, C., \& Potgieter, J. (2000). An investigation of phosphate ion adsorption from aqueous solution by fly ash and slag. Cement and Concrete Research, 30, 823-826.

Arias, C., Del Bubba, M., \& Brix, H. (2001). Phosphorus removal by sands for use as media in subsurface flow constructed reed beds. Water Research, 35, 1159-1168.

Arias, M., Da Silva-Carballal, J., García-Río, L., Mejuto, J., \& Núñez, A. (2006). Retention of phosphorus by iron and aluminum-oxides-coated quartz particles. Journal of Colloid and Interface Science, 295, 65-70.

Biswas, B. K., Inoue, K., Ghimire, K. N., Harada, H., Ohto, K., \& Kawakita, H. (2008). Removal and recovery of phosphorus from water by means of adsorption onto orange waste gel loaded with zirconium. Bioresource Technology, 99, 8685-8690.

Cheung, K., \& Venkitachalam, T. (2000). Improving phosphate removal of sand infiltration system using alkaline fly ash. Chemosphere, 41, 243-249.

Chitrakar, R., Tezuka, S., Sonoda, A., Sakane, K., Ooi, K., \& Hirotsu, T. (2006). Selective adsorption of phosphate from seawater and wastewater by amorphous zirconium hydroxide. Journal of Colloid and Interface Science, 297, 426-433.

D’Arcy, M., Weiss, D., Bluck, M., \& Vilar, R. (2011). Adsorption kinetics, capacity and mechanism of arsenate and phosphate on a bifunctional $\mathrm{TiO}_{2}-\mathrm{Fe}_{2} \mathrm{O}_{3}$ bi-composite. Journal of Colloid and Interface Science, 364, 205-212.

De La Noue, J., \& de Pauw, N. (1988). The potential of microalgal biotechnology: a review of production and uses of microalgae. Biotechnology Advances, 6, 725-770.

De-Bashan, L., \& Bashan, Y. (2004). Recent advances in removing phosphorus from wastewater and its future use as fertilizer (1997-2003). Water Research, 38, 4222-4246.

Deliyanni, E. A., Peleka, D. N., \& Lazaridis, N. K. (2007). Comparative study of phosphates removal from aqueous solutions by nanocrystalline akaganéite and hybrid surfactant-akaganéite. Separation and Purification Technology, $52,478-486$.

Donnert, D., \& Salecker, M. (1999). Elimination of phosphorus from waste water by crystallization. Environmental Technology, 20, 735-742.

Freundlich, H. M. F. (1906). Über die adsorption in lösungen. Zeitschrift für Physikalische Chemie, 57A, 385-470.

Giesler, R., Andersson, T., Lovgren, L., \& Persson, P. (2005). Phosphate sorption in aluminum and iron-rich humus soils. Soil Science Society of America Journal, 69, 77-86.

Harver, O. R., \& Rhue, R. D. (2008). Kinetics and energetics of phosphate sorption in a multi-component $\mathrm{Al}(\mathrm{III})-\mathrm{Fe}(\mathrm{III})$ hydr(oxide) sorbent system. Journal of Colloid and Interface Science, 322, 384-393.

Hsia, T. H., Lo, S. L., Lin, C. F., \& Lee, D. Y. (1994). Characterization of arsenate adsorption on hydrous iron-oxide using chemical and physical methods. Colloids and Surfaces A: Physicochemical and Engineering Aspects, 85, 1-7.

Huang, W. W., Wang, S. B., Zhu, Z. H., Li, L., Yao, X. D., Rudolph, V., \& Haghseresht, F. (2008). Phosphate removal from wastewater using red mud. Journal of Hazardous Materials, 158, 35-42.
Kang, S., Choo, K., \& Lim, K. (2003). Use of iron oxide particles as adsorbents to enhance phosphorus removal from secondary wastewater effluent. Separation Science and Technology, 38, 3853-3874.

Khelifi, O., Kozuki, Y., Murakami, H., Kurata, K., \& Nishioka, M. (2002). Nutrients adsorption from seawater by new porous carrier made from zeolitized fly ash and slag. $M a-$ rine Pollution Bulletin, 45, 311-315.

Langmuir, I. (1916). The constitution and fundamental properties of solids and liquids. Part I: solid. Journal of the American Chemical Society, 38, 2221-2295.

Li, H., Ru, J. Y., Yin, W., Liu, X. H., Wang, J. Q., \& Zhang, W. D. (2009). Removal of phosphate from polluted water by lanthanum doped vesuvianite. Journal of Hazardous Materials, 168, 326-330.

Liu, H., Sun, X., Yin, C., \& Hu, C. (2008). Removal of phosphate by mesoporous $\mathrm{ZrO}_{2}$. Journal of Hazardous Materials, 151, 616-622.

Long, F., Gong, J.-L., Zeng, G.-M., Chen, L., Wang, X.-Y., Deng, J.-H., Niu, Q.-Y., Zhang, H.-Y., \& Zhang, X.-R. (2011). Removal of phosphate from aqueous solution by magnetic Fe-Zr binary oxide. Chemical Engineering Journal, 171, 448-455.

McBride, M. B. (1997). A critique of diffuse double layer models applied to colloid and surface chemistry. Clays and Clay Minerals, 45, 598-608.

Morse, G. K., Brett, S. W., Guy, J. A., \& Lester, J. N. (1998). Review: phosphorus removal and recovery technologies. Science of the Total Environment, 212, 69-81.

Ouz, E., Gürses, A., \& Canpolat, N. (2003). Removal of phosphate from wastewaters. Cement and Concrete Research, 33, 1109-1112.

Persson, P., Nilsson, N., \& Sjöberg, S. (1996). Structure and bonding of orthophosphate ions at the iron oxide-aqueous interface. Journal of Colloid and Interface Science, 177, 263-275.

Puckett, L. (1995). Identifying the major sources of nutrient water pollution. Environmental Science Technology, 29, 408-414.

Ren, Z. M., Zhang, G. S., \& Chen, J. P. (2011). Adsorptive removal of arsenic by an iron-zirconium binary oxide adsorbent from water. Journal of Colloid and Interface Science, 358, 230-237.

Rentza, J. A., Turnera, I. P., \& Ullmanb, J. L. (2009). Removal of phosphorus from solution using biogenic iron oxides. Water Research, 43, 2029-2035.

Rodrigues, L. A., \& Silva, M. L. C. P. D. (2009). An investigation of phosphate adsorption from aqueous solution onto hydrous niobium oxide prepared by co-precipitation method. Colloids and Surfaces A: Physicochemical and Engineering Aspects, 334, 191-196.

Ryden, J. C., \& McLaughlin, J. K. J. (1977). Mechanisms of phosphate sorption by soils and hydrous ferric oxide gel. Journal of Soil Science, 28, 72-92.

Seida, Y., \& Nakano, Y. (2002). Removal of phosphate by layered double hydroxides containing iron. Water Research, 36, 1306-1312.

Suzuki, T. M., Bomani, J. O., Matsunaga, H., \& Yokoyama, T. (2000). Preparation of porous resin loaded with crystalline hydrous zirconium oxide and its application to the removal 
of arsenic. Reactive and Functional Polymers, 43, 165172.

Tanada, S., Kabayama, M., Kawasaki, N., Sakiyama, T., Nakamura, T., Araki, M., \& Tamura, T. (2003). Removal of phosphate by aluminum oxide hydroxide. Journal of Colloid and Interface Science, 257, 135-140.

Tian, S., Jiang, P., Ning, P., \& Su, Y. (2009). Enhanced adsorption removal of phosphate from water by mixed lanthanum/aluminum pillared montmorillonite. Chemical Engineering Journal, 151, 141-148.

Ugurlu, A., \& Salman, B. (1998). Phosphorus removal by fly ash. Environment International, 24, 911-918.

Urnius, E., Klippenstein, S., \& Protasiewicz, J. (2000). Sterically promoted zirconium-phosphorus [pi]-bonding: structural investigations of $[\mathrm{Cp} 2 \mathrm{Zr}(\mathrm{Cl})\{\mathrm{P}(\mathrm{H}) \mathrm{Dmp}\}]$ and $[\mathrm{Cp} 2 \mathrm{Zr} \mathrm{P}$ (H) Dmp 2](Dmp=2, 6-Mes2C6H3). Inorganica Chimica Acta, 297, 181-190.
Van Voorthuizen, E., Zwijnenburg, A., \& Wessling, M. (2005). Nutrient removal by NF and RO membranes in a decentralized sanitation system. Water Research, 39, 3657-3667.

Ye, H. P., Chen, F. Z., Sheng, Y. Q., Sheng, G. Y., \& Fu, J. M. (2006). Adsorption of phosphate from aqueous solution onto modified palygorskites. Separation and Purification Technology, 50, 283-290.

Zeng, L., Li, X., \& Liu, J. (2004). Adsorptive removal of phosphate from aqueous solutions using iron oxide tailings. Water Research, 38, 1318-1326.

Zhang, G. S., Liu, H. J., Liu, R. P., \& Qu, J. H. (2009). Removal of phosphate from water by a $\mathrm{Fe}-\mathrm{Mn}$ binary oxide adsorbent. Journal of Colloid and Interface Science, 335, 168174.

Zhao, D., \& Sengupta, A. (1998). Ultimate removal of phosphate from wastewater using a new class of polymeric ion exchangers. Water Research, 32, 1613-1625. 